\title{
Replication of the association of the COG6 gene with juvenile idiopathic arthritis (JIA)
}

\author{
A Hinks ${ }^{1 *}$, J Cobb ${ }^{1}$, P Martin ${ }^{1}$, E Flynn' ${ }^{1}$ S Eyre ${ }^{1}$, J Packham², Childhood Arthritis Prospective Study (CAPS), \\ BSPAR study group, A Barton', J Worthington', W Thomson' ${ }^{1}$ \\ From 18th Pediatric Rheumatology European Society (PReS) Congress \\ Bruges, Belgium. 14-18 September 2011
}

\section{Background}

A large US JIA case control study investigating SNPs previously implicated in autoimmune diseases recently identified three novel JIA loci, protein tyrosine phosphatase, non-receptor type 2 (PTPN2), conserved oligomeric golgi complex component 6 (COG6) and angiopoietin 1 (ANGPT1). We have previously shown association of SNPs in the PTPN2 gene in our UK JIA cohort.

\section{Aim}

To test whether the two additional loci also confer susceptibility to JIA in a UK cohort.

\section{Methods}

Two SNPs, rs7993214, near the COG6 gene and rs1010824, near the ANGPT1 gene, were genotyped in UK JIA cases $(\mathrm{n}=817)$ and the genotype and allele frequency data compared with those for healthy controls $(n=5196)$ extracted from the Wellcome Trust case control consortium 2 (WTCCC2) European Genomephenome Archive (EGA). The Cochrane-Armitage trend test implemented in PLINK was performed and allelic odds ratios (ORs) and their 95\% confidence intervals (CIs) calculated.

\section{Results}

This study had $>90 \%$ power to detect an effect equivalent to that identified for these loci in the original study. No association was found for the SNP in ANGPT1 (ptrend $=0.85)$. The SNP near the COG6 gene,

\footnotetext{
* Correspondence: Anne.Hinks@manchester.ac.uk

${ }^{1}$ Arthritis Research UK Epidemiology Unit, Manchester Academic Health Science Centre (MAHSC), Stopford Building, University of Manchester, Manchester, UK

Full list of author information is available at the end of the article
}

rs7993214, was significantly associated with JIA overall (ptrend $=0.03$ OR 0.9 95\% CI 0.81-0.99). Analysis of only the oligoarthritis and RF negative polyarthritis subtypes, the subtypes investigated in the US study, revealed a trend towards association (ptrend $=0.06 \mathrm{OR}$ 0.9 95\% CI 0.8-1.01). Our study suggests however that this SNP maybe associated in other JIA subtypes, indeed despite comparatively small numbers $(n=123)$ the association was also significant in the systemic onset subtype $(\mathrm{p}=0.03)$. Meta-analysis of this study with the original study provided genome wide significant association of this SNP with JIA (combined p-value $=8.5 \times 10^{-7} \mathrm{OR}$ $0.8495 \%$ CI $0.78-0.9$ ) with no evidence of heterogeneity between the two studies.

\section{Conclusions}

We present replication of the association of a SNP near the COG6 gene and JIA. Meta-analysis of this study with the original US study provided genome wide significance for this locus in oligoarticular JIA and RF negative polyarthritis JIA. The SNP lies within an intergenic region between the COG6 and FOXO1 genes. COG6 is a component of the conserved oligomeric golgi complex, which plays a role in glycoprotein modification and intracellular transport. FOXO1 belongs to the forkhead family of transcription factors and may be important in regulatory $\mathrm{T}$ cell development and function. Further genetic analysis will be required to identify the causal SNP and gene important in JIA susceptibility.

\footnotetext{
Author details

${ }^{1}$ Arthritis Research UK Epidemiology Unit, Manchester Academic Health Science Centre (MAHSC), Stopford Building, University of Manchester, Manchester, UK. ${ }^{2}$ Haywood Hospital, University Hospital of North Staffordshire, Stoke on Trent, Staffordshire, UK.
}

C 2011 Hinks et al; licensee BioMed Central Ltd. This is an open access article distributed under the terms of the Creative Commons Attribution License (http://creativecommons.org/licenses/by/2.0), which permits unrestricted use, distribution, and reproduction in any medium, provided the original work is properly cited. 
- Convenient online submission

- Thorough peer review

- No space constraints or color figure charges

- Immediate publication on acceptance

- Inclusion in PubMed, CAS, Scopus and Google Scholar

- Research which is freely available for redistribution 